論文

날개-평판 접합부에서의 날개 앞전 판 최적화를 통한 유동특성 향상

조종재*, 김귀순**

\title{
Improvement of the flow around airfoil/flat-plate junctures by optimization of the leading-edge fence
}

Jongjae Cho* and Kuisoon Kim**

\begin{abstract}
3-Dimensional flow which is represented by horseshoe vortex is generated as a type of secondary flow about the main flow. As well, it causes the flow loss. The present study deals with the leading edge fence shape on a wing-body junction to decrease a horseshoe vortex, one of the main factors to generate the secondary flow losses. The shape of leading-edge fence was optimized with the design variables of the installed height, length, width, and thickness of the fence as the design variables. Approximate optimization design method is used as the optimization. The study was investigated using FLUENT $^{\mathrm{TM}}$ and iSIGHT $^{\mathrm{TM}}$. Total pressure coefficient of the optimized design case was decreased about $7.5 \%$ compare to the baseline case.
\end{abstract}

\section{초 록}

말굽와류로 대표되는 3차원 유동현상은 필연적으로 주유동에 대한 2차 유동의 형태로 발생되며, 유동손실을 유발하게 된다. 본 논문에서는 2차유동 손실을 일으키는 주요 요인 중의 하나인 말굽와류의 강도를 감쇄시키기 위해 일반적인 날개 앞전에 설치한 판에 대 해, 판의 설치 높이, 길이, 폭 및 두께 등의 형상변수를 설계변수로 정하여 이를 최적화 하였다. 근사최적설계 기법을 이용 최적화를 수행하였으며, $\mathrm{FLUENT}^{\mathrm{TM}}$ 와 $\mathrm{iSIGHT}^{\mathrm{TM}}$ 를 이 용하였다. 최적화 수행결과, 기준 모델의 경우보다 전압력 계수가 약 $7.5 \%$ 감소하였다.

Key Words : Horseshoe Vortex(말굽 와류), Secondary Flow Losses(2차 유동 손실), Leading-Edge Fence(날개 앞전 판), Optimization(최적화)

\begin{tabular}{|c|c|c|c|}
\hline \multicolumn{4}{|c|}{ dilleticia } \\
\hline $\mathrm{C}_{\mathrm{pt}}$ & : total pressure coefficient $=$ & $\mathrm{k}$ & : turbulent kinetic energy \\
\hline \multirow[b]{2}{*}{ NTKE } & $\left(P_{t . i n}-P_{t}\right) / 0.5 \rho U_{i n}^{2}$ & $\mathrm{U}$ & $:$ mean velocity $(\mathrm{m} / \mathrm{s})$ \\
\hline & $\begin{array}{l}\text { : normalized turbulent kinetic energy } \\
=k / U_{i n}^{2}\end{array}$ & $\mathrm{x}, \mathrm{y}, \mathrm{z}$ & $\begin{array}{l}\text { streamwise, crossed streamwise, } \\
\text { and spanwise directions }\end{array}$ \\
\hline & & 1 & : length(m) \\
\hline \multirow{2}{*}{\multicolumn{2}{|c|}{$\begin{array}{l}\text { † 2009년 6월 3일 접수 2009년 8월 27일 심사완료 } \\
\text { * 정회원, 부산대학교 항공우주공학과 대학원 } \\
\text { ** 정회원, 부산대학교 항공우주공학과 } \\
\text { 교신저자, Email : kuskim@pusan.ac.kr } \\
\text { 부산시 금정구 장전동 산30번지 }\end{array}$}} & $\rho$ & : density $\left(k g / m^{3}\right)$ \\
\hline & & $\delta_{99}$ & $\begin{array}{l}\text { : boundary layer thickness at the } \\
\text { rate of } U / U_{i n}=0.99\end{array}$ \\
\hline
\end{tabular}


$R_{a d}^{2} \quad$ : adjusted coefficient of determination

$$
=1-\frac{(n-1)\left(1-R^{2}\right)}{n-p-1}
$$

n : number of experimental points

$\mathrm{p} \quad$ : number of response function coefficient

$R^{2} \quad$ : coefficient of determination $=1-\frac{S S E}{S S T}$

SSE : residual sum of squares

$$
=S S T-S S R
$$

SST : total sum of squares

$=\sum\left(y_{i}-\bar{y}\right)^{2}$
2차원 경계층과 평면에 수직한 물체에 의해 발생하는 역압력구배(Adverse pressure gradient) 의 상호작용에 기인하여 나타나는 말굽와류 (Horseshoe vortex) 현상은 익형 및 익렬 앞전 (Leading edge)에서의 3차원 유동, 다리 교각에 서의 유동, 평지에 서 있는 건물 주위의 유동 등 과 같이 흔히 관찰될 수 있는 유체역학의 현상일 뿐만 아니라, 말굽와류를 발생시키는 물체 주위 의 열 및 물질전달 현상과 연관되어 오래전부터 많은 연구의 대상이 되어왔다. 말굽와류로 대표 되는 이러한 3 차원 유동현상은 필연적으로 주유 동에 대한 2차 유동(Secondary flow)의 형태로 발생됨으로, 유동손실을 유발하게 된다. 하지만, 말굽와류발생은 평면 경계층이 존재하는 이상 피 할 수 없는 현상이므로 말굽와류가 발생하는 물 체의 기하학적인 형상을 변화시켜 역압력구배가 발생하는 원인 및 현상을 억제시킴으로써 유동손 실을 감소시킬 수 있다.

따라서 이러한 방법을 이용하여 유동손실을 줄이기 위한 연구가 필요하며 오래전부터 관련 기초연구 및 응용연구가 진행되어왔다. 기초연구 로 Eckerle와 Langston[1]은 말굽와류의 형성과 정을 표면유동가시화, 표면정압력측정 등의 실험 을 통해 상세하게 고찰하였다. 그리고 말굽와류 가 발생하는 물체의 기하학적인 형상을 변화를 통한 말굽와류의 발생을 제어하기 위한 응용연구 로 Kubendran, Harvey[2]는 길이와 높이가 다른 직선형태의 날개 앞전 Fillet 형상과 곡선형태의 날개 앞전 Fillet 형상에 대해 연구하였으며, Devenport[3]는 "Strake"라 명명한 곡선형태의
SSR : regression for sum of squares $=\sum\left(\hat{y_{i}}-\bar{y}\right)^{2}$

$y_{i} \quad$ : dependent variable at sample point

$\bar{y}_{i} \quad$ : mean value of $y_{i}$

$\hat{y_{i}} \quad$ : dependent variable at regression function

Subscripts

$\begin{array}{cl}\text { in } & : \text { inlet } \\ 4.46 & : \text { plane at } \mathrm{x} / \mathrm{t}=4.46 \\ \mathrm{ad} & : \text { adjusted } \\ \mathrm{t} & : \text { total }\end{array}$

$\mathrm{FH}, \mathrm{FL}, \quad$ : fence height, length, thickness and FT, FW width

앞전 Fillet을 이용하여 실험적인 방법으로 연구 를 하였으며, 그 효과를 확인하였다. Zess, Thole[4]은 날개 앞전 Fillet 형상에 대해 Laser Doppler Velocimeter를 이용하여 터빈 유로의 4 지점의 면에 대해 유동장을 측정하였으며 이를 RNG k- $\varepsilon$ 난류모델을 사용한 수치해석결과와 비 교하였다. 또한, $\mathrm{Cho[5]}$ 는 날개 앞전에 판(Fence) 를 설치하여 날개 선단에서의 유동정체로 인한 높이 방향으로의 압력구배로 인해 날개 선단에서 바닥면으로 흐르는 유동의 흐름을 차단하는 방법 으로 말굽와류 발생강도를 제어하였다. 하지만 이는 매개변수에 대한 연구의 개념으로, 몇몇의 경우에 한정하여 수행되어졌다.

따라서 본 논문에서는 최적설계 기법을 통해 Cho[5]에 의해 연구된 날개 앞전 판의 말굽와류 발생강도 약화에 의한 유동 특성 향상 효과를 극 대화 하도록 하였다. 하지만 이러한 최적설계 결 과를 얻기 위해서는 국부최적화 기법을 사용할 경우, 수십 회 이상의 해석 횟수가 요구되며 전 역최적화 기법을 사용할 경우에는 수백회 이상의 해석횟수를 필요로 한다. 또한 설계를 완료하기 위해 소요되는 시간은 일 회의 해석시간에 비례 하므로 설계 결과를 얻기 위해 소요되는 시간이 너무 오래 걸리는 문제점이 있다. 이와 같은 문 제점을 극복하고 최적설계의 효율성을 높이기 위 해서 본 논문에서는 1970년대에 도입된 근사최적 설계방법(Approximate optimization design method)을 이용하여 연구를 수행하였다. 최적화 를 위해 최적화 상용프로그램인 $\mathrm{iSIGHT}^{\mathrm{TM}}$ 를 이 용하였으며, 상용 프로그램인 $\mathrm{Gambit}^{\mathrm{TM}}$ 을 형상 모델링 및 격자생성을 위해 사용하였다. 유동해 석을 위해는 상용 프로그램인 $\mathrm{FLUENT}^{\mathrm{TM}}$ 를 사용 
하였다. 그리고 모든 과정이 순차적으로 실행될 수 있도록 통합하여 연구를 수행하였다.

\section{2. 본 론}

\section{1 수치해석 기법 및 모델}

본 연구에 사용된 해석 기본모델로는 Olcmen and Simpson [6][7]의 모델을 사용하였다. 블레 이드는 NACA 0020의 기본 형태에 앞전의 횡단 면 (Cross Section)이 3:2의 타원 형태를 가진다. 코드길이는 $30.5 \mathrm{~cm}$, 두께는 $7.17 \mathrm{~cm}$ 이다.

유동해석을 위해 3차원 비압축성 Navier-Stokes 방정식 해법을 이용하였으며 계산은 모두 2차의 공간정확도 조건으로 하였다. 또한 경계면은 Jones와 Clarke[7]의 연구에서 설정한 것처럼, Fig. 1과 같이 설정하였다. 경계조건은 유입유동 의 경우 속도를 고정하는 Velocity inlet 조건을 사용하였고 유출유동은 Preassure outlet 조건을 사용하였다. 입구 속도 $\left(\mathrm{U}_{\mathrm{in}}\right)$ 는 $27 \mathrm{~m} / \mathrm{s}$ 에서 경계 층의 두께 $\left(\delta_{99}\right)$ 는 $36 \mathrm{~mm}$, 난류강도는 $0.2 \%$ 이며 블레이드 두께 기준 레이놀즈수는 $1.15 \times 10^{5}$ 이다. 총 계산격자는 약 69만개이다.

난류모델은 Zess와 Thole[4]의 연구에서 검증 된 Yakhot, Orszag[9]의 RNG k- $\varepsilon$ 모델을 사용하 였으며 벽면처리기법으로는 Non-equilibrium 기 법을 사용하였다.

\section{2 근사최적설계 기법}

근사최적설계 기법은 선정된 설계변수(Design variable)를 바탕으로 적절한 설계변수 분포를 선 택하는 실험계획법(Design of experiments)과 실 험계획법을 통해 만들어진 설계변수 분포와 목적 함수(Object function) 사이의 관계를 수학적 모 델로 근사화하여 근사면을 모델링하는 근사해석

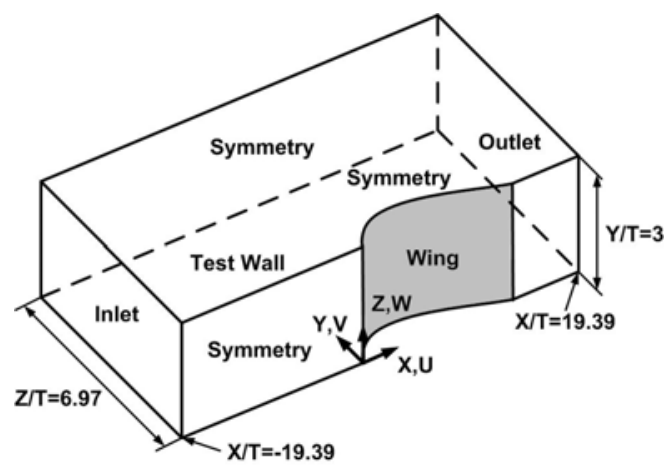

Fig. 1. Perspective View of Wing-Body Junction
모델(Approximate analysis model) 기법, 그리고 근사해석모델 기법으로 만들어진 근사면에 대해 최적화를 수행하는 최적화 기법으로 구성된다.

실험계획법으로는 설계영역 내의 실험점들을 균일하게 분포되도록 선택하는 Optimal latin hypercube[10] 방법을 이용하였으며, 총 40개의 샘플점을 선정하였다. 계산 수렴조건은 모든 방정 식이 $10^{-5}$ 까지 수렴하도록 하였으며 샘플점 하나 당 90 분이 소요되었다. $\mathrm{iSIGHT}^{\mathrm{TM}}$ 에 포함된 근사 해석모델 기법으로는 반응면 기법(RSM, Response surface model)[11]과 RBF (Radial basis function approximation)기법이 있으며 본 연구에서는 계산 시간이 비교적 빠른 반응면 기법을 이용하여 근사 면을 생성하였다. 최적화 기법으로 경사탐색 알고 리즘(Gradient based algorithm)과 달리 여러 지 점의 국부적인 최적값을 구분할 수 있으며 최적화 의 수렴성, 신뢰성 그리고 안정성 등이 뛰어나 가 장 널리 사용되고 있는 유전자 알고리즘(Genetic algorithm)을 이용하였다.

\section{3 최적설계 절차}

근사최적화설계 기법을 적용하여 말굽와류를 감쇄시키는 성능을 가진 날개 앞전 판을 최적화 하기 위해 Fig. 2와 같은 최적설계 절차를 거쳐 최적화를 수행하였다.

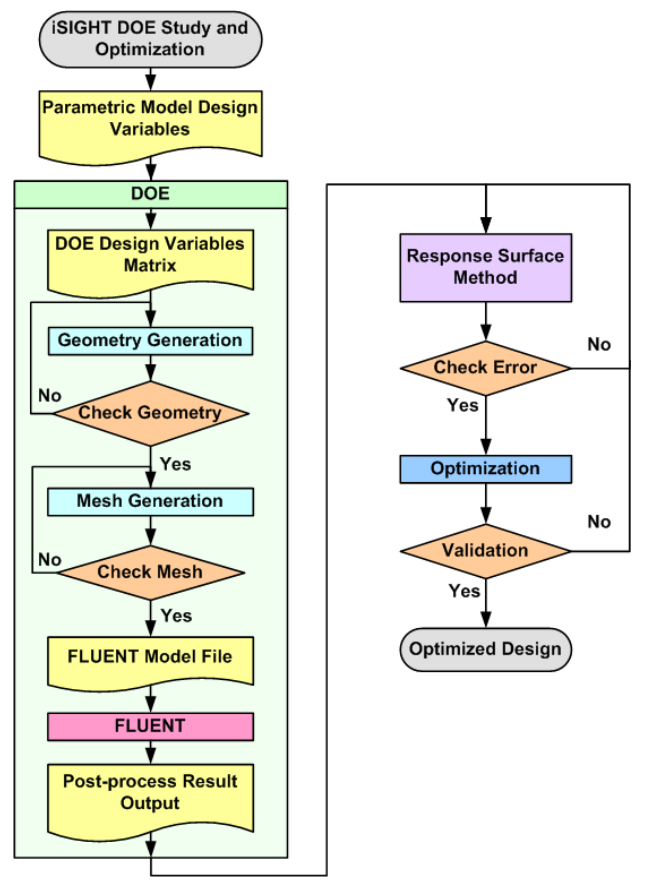

Fig. 2. Flow Chart of Optimization Design Algorithm 
최적의 목적함수 값을 얻기 위한 설계변수를 선정하고 이를 기반으로 Optimal latin hypercube 을 이용한 실험계획법으로 설계변수의 분포를 만든 다. 그리고 상용 설계 및 격자 생성 프로그램인 $\mathrm{Gambit}^{\mathrm{TM}}$ 을 이용하여 설계변수에 대한 모델을 디 자인을 완료한 후에 격자를 생성한다. 생성된 모델 과 격자를 $\mathrm{FLUENT}^{\mathrm{TM}}$ 로 넘겨 전산해석을 실시하고 계산된 결과에서 목적함수 값을 추출하여 반응면 기법을 이용하여 반응면을 생성한다. 그리고 생성 된 반응면의 오차정도를 수정결정계수 $\left(R_{a d}^{2}\right)$ 값으로 확인하여 반응면의 정확도를 측정한다. 수정결정계 수 값이 1 에 근접할수록 반응면은 실제함수에 근접 하다고 할 수 있다. 오차가 클 경우에는 반응면의 정확도를 확보할 때까지 샘플점을 추가, 제거 또는 재배열하여 원하는 정확도의 반응면을 재생성한다. 정확도가 확보된 반응면에서 유전자 알고리즘을 통 해 최적값을 찾은 다음, 최적값의 신뢰성 확보를 위해 획득한 최적값에 해당하는 설계변수로 $\mathrm{FLUENT}^{\mathrm{TM}}$ 를 이용하여 계산한 결과값과 근사최적 화설계 기법으로 찾은 최적값을 비교하여 오차정도 를 확인한다. 결과값이 오차정도를 만족할 경우에 는 결과값을 최종 최적값으로 획득하며, 그렇지 못 할 경우에는 오차정도를 만족할 때까지 샘플점을 추가, 제거 또는 재배열하여 반응면을 재 생성한다.

\section{4 설계변수 및 목적함수}

최적화를 위해서는 원하는 목적함수를 찾을 때까지 설계변수를 바꾸면서 반복계산을 수행해 야 된다. 이때 설계변수는 주어진 제약조건 (Constraint condition)을 만족해야 한다.

$$
\begin{gathered}
0.2 \leq 1_{\mathrm{FH}} / \delta_{99} \leq 0.35 \\
0.75 \leq 1_{\mathrm{FL}} / \delta_{99} \leq 1.05 \\
0.4 \leq 1_{\mathrm{FW}} / \delta_{99} \leq 0.8 \\
0.04 \leq 1_{\mathrm{FT}} / \delta_{99} \leq 0.2 \\
\text { Minimize } F(\vec{X})=\frac{\left.\frac{\int C_{P t} \rho\left|\vec{u} \cdot \overrightarrow{d A_{i}}\right|}{\int \rho\left|\vec{u} \cdot \overrightarrow{A_{i}}\right|}\right|_{x / t=4.46}}{\left.\frac{\int C_{P t} \rho\left|\vec{u} \cdot \overrightarrow{A_{i}}\right|}{\int \rho\left|\vec{u} \cdot \overrightarrow{A_{i}}\right|}\right|_{\text {Baseline }}}
\end{gathered}
$$

설계변수는 Fig. 3 과 같이 날개 앞전 판의 형 상을 구성하는 변수인 판의 높이 $\left(\mathrm{l}_{\mathrm{FH}}\right)$ 및 길이 $\left(\mathrm{l}_{\mathrm{FL}}\right)$, 폭 $\left(\mathrm{l}_{\mathrm{FW}}\right)$, 두께 $\left(\mathrm{l}_{\mathrm{FT}}\right)$ 등을 경계층의 두께로 무 차원화한 것으로 하였다. 설계변수의 보조제약조 건(Side constraints)은 이전 연구와 형상간섭, 제 작가능성 등을 고려하여 $\mathrm{Eq}$. 1 과 같이 정하였다.
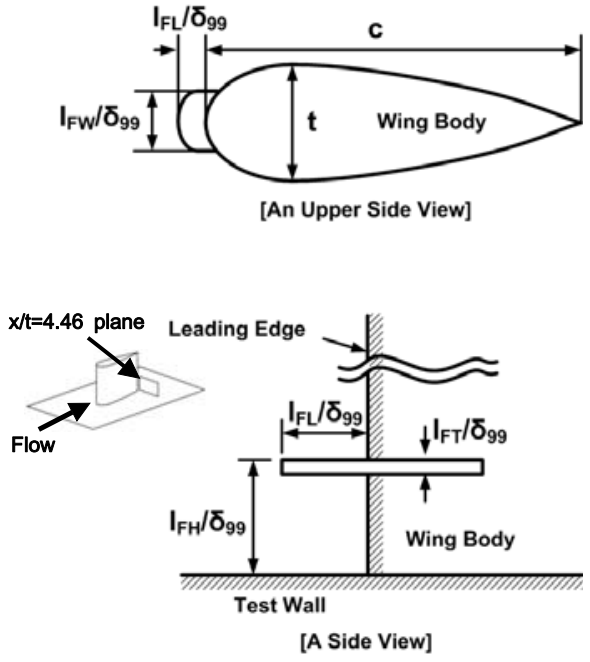

Fig. 3. Schematic Views of Fence

목적함수는 Fig. 3에 표시된 x/t가 4.46인 면에 서 전압력 손실계수(Total pressure loss coefficient, $\mathrm{C}_{\mathrm{Pt}}$ )의 질량가중평균(Mass-weighted average)한 값(Eq. 2)을 기준 모델(Baseline model)에 대한 값으로 무차원화한 값을 최소화 하는 것으로 하였다. $\mathrm{x} / \mathrm{t}$ 가 4.46 인 지점은 날개 뒷전(Tailing edge)에서 $\mathrm{x} / \mathrm{t}$ 가 0.16 떨어진 지점 으로, 뒷전에서 발생하는 후류(Wake)와 모서리와 류(Corner vortex), 그리고 말굽와류가 서로 상호 작용하는 지점이다.

\section{3. 결과 및 고찰}

앞서 선택한 설계변수와 제약조건, 목적함수를 바탕으로 근사최적화를 실시하였다. 그 결과로 Table 1과 같이 수정결정계수 $\left(R_{a d}^{2}\right.$, Adjusted coefficient of determination)가 허용치 0.9 이상 인 0.959 가 나왔으며, 생성된 근사면을 통해 획득 한 최적값과 획득한 최적값에 해당하는 설계변수 로 전산해석한 결과값과의 오차는 $0.265 \%$ 로 나타 났다. 이를 통해 근사해석모델 기법으로 형성한 근사면의 신뢰성을 확보할 수 있었다. 그리고 형 성한 근사면을 바탕으로 최적화를 실시한 결과 Table 2와 같은 최적 설계변수를 획득할 수 있다.

Fig. 4(a) (c)는 기준 모델과 $\mathrm{Cho[5],} \mathrm{그리고} \mathrm{최}$ 적화를 통해 획득한 형상에 대한 날개 앞전 부근 에서의 Pathline을 나타낸 것으로 $\mathrm{Cho[5]에} \mathrm{의한}$ 연구의 경우, 말굽와류가 와해되어 거의 나타나 지 않는 것을 알 수 있다. 하지만 최적화 결과의 경우, 기준 모델의 경우와 반대 방향으로 회전하 
Table 1. Summary of Errors

\begin{tabular}{c|c}
\hline$R_{a d}^{2}$ & 0.959 \\
\hline $\begin{array}{c}\text { Difference Between Prediction } \\
\text { and Actual Results (\%) }\end{array}$ & 0.265 \\
\hline
\end{tabular}

Table 2. Summary of Optimized Leading Edge Fence Geometry

\begin{tabular}{c|c}
\hline Design Variables & Results of Optimization \\
\hline \hline $1_{\mathrm{FH}} / \delta_{99}$ & 0.25 \\
\hline $1_{\mathrm{FL}} / \delta_{99}$ & 0.82 \\
\hline $1_{\mathrm{FW}} / \delta_{99}$ & 0.54 \\
\hline $1_{\mathrm{FT}} / \delta_{99}$ & 0.16 \\
\hline
\end{tabular}

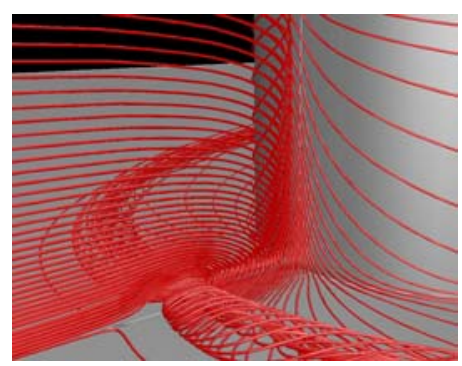

(a) Baseline, No Fence

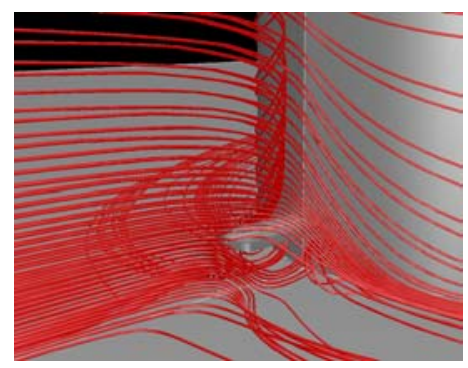

(b) Parametric Study of Cho[5]

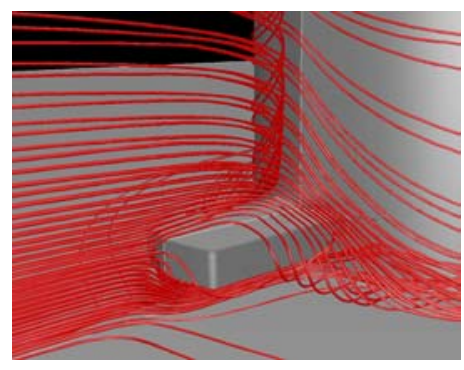

(c) Optimized Design

Fig. 4. Pathlines at Leading Edge Plane

는 말굽와류가 발생하는 것을 볼 수 있다. 이것 은 판의 두께가 두꺼워짐에 따라 판의 옆면에서
유동박리에 의한 순환유동과 판 윗면의 상류 유 동이 교차하면서 기존의 회전방향과 반대방향의 말굽와류가 형성되게 된다. 이렇게 발생한 말굽 와류는 회전방향이 이와 반대인 판의 아래 바닥 면에서 발생하는 약한 말굽와류와 합쳐져 이를 상쇄시키고, 날개면과 바닥면이 교차하는 지점에 서 발생하는 모서리와류와는 합쳐지지 않고 모서 리 와류를 바닥면에서 밀어 올리면서 그 강도를 감쇄시킨다.

Fig. 5(a) (c)는 각 형상에 대한 날개 앞전 면 에서의 수정 NTKE $\left(\mathrm{NTKE}_{\mathrm{ad}}\right)$ 값으로 날개 앞전 면에서의 NTKE값을 기준 모델의 질량가중평균 한 NTKE값으로 나눈 것이다. Fig. 5(a)에서 볼수 있듯이 기준 모델의 경우, $(-0.27(\mathrm{x} / \mathrm{t}), 0.03(\mathrm{z} / \mathrm{t}))$ 인 지점에서 강한 난류운동에너지 중심이 형성되 는 것을 알 수 있다. 하지만 $\mathrm{Cho[5]의} \mathrm{형상과} \mathrm{같}$ 이 날개 앞전의 높이 방향으로의 정압력(Static press- ure) 구배에 의해 발생하는 날개 앞전면에 서 바닥면으로 흐르는 유동을 판을 이용하여 차 단함으로써, 기존의 경우에 발생하던 강한 난류 운동에너지의 중심이 와해되는 것을 알 수 있다. 최적화 기법을 이용하여 $\mathrm{x} / \mathrm{t}=4.46$ 인 면에서의 전압력 손실이 최소가 되도록 목적함수를 설정하 여 획득한 결과에 대한 $\mathrm{NTKE}_{\mathrm{ad}}$ 값을 Fig. 5(c)에 나타내었다. Cho[5]의 결과에 비해 판의 길이가 길어지고 두께가 두꺼워진 것을 알 수 있다. 판 의 두께가 두꺼워짐에 따라 Cho[5]의 결과에 비 해 판의 앞전에서 유동정체와 유동박리가 크게 발생하며, 판의 아래 면에서는 유동박리에 의한 순환유동이 Cho[5]의 결과에 비해 크게 나타나는 것을 알 수 있다. 이러한 결과로 인해 판의 앞전 과 아래 면에서의 높은 값을 나타내는 난류운동 에너지의 영역 및 크기가 증가한 것을 알 수 있 다. 판의 앞전의 난류운동에너지의 경우, $\mathrm{Cho[5]}$ 의 결과에 비해 약 $18 \%$ 정도 증가하였다. 또한 판의 길이가 길어짐에 따라 판의 윗면에서도 높 은 난류운동에너지 영역이 형성되는 것을 볼 수 있으며 이 역시 $\mathrm{Cho[5]}$ 의 결과에 비해 약 $5 \%$ 정 도 증가하였다.

Fig. 6 은 기준 모델에 대한 $\mathrm{x} / \mathrm{t}=4.46$ 인 면에서 의 NTKE $\mathrm{Ed}_{\mathrm{ad}}$ 값이다. Fig. 6에서 볼 수 있듯이 날개 앞전 면에서 발생한 강한 말굽와류와 모서리 와 류, 날개면에서 바닥면으로 흐르는 유동 등에 의 해 $(0.1(\mathrm{y} / \mathrm{t}), \quad 0.1(\mathrm{z} / \mathrm{t}))$ 인 지점과 $(1.1(\mathrm{y} / \mathrm{t})$ $0.25(\mathrm{z} / \mathrm{t}))$ 인 지점에서 높은 난류운동에너지 영역 이 나타나는 것을 알 수 있다. 이러한 바닥면의 낮은 운동에너지를 갖는 경계층 영역을 통과하는 와류로 인해 발생하는 점성 저항은 전압력 손실 로 나타난다. 


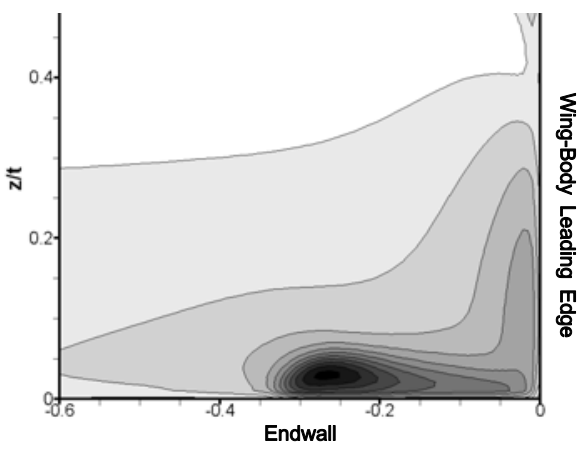

(a) Baseline, No Fence

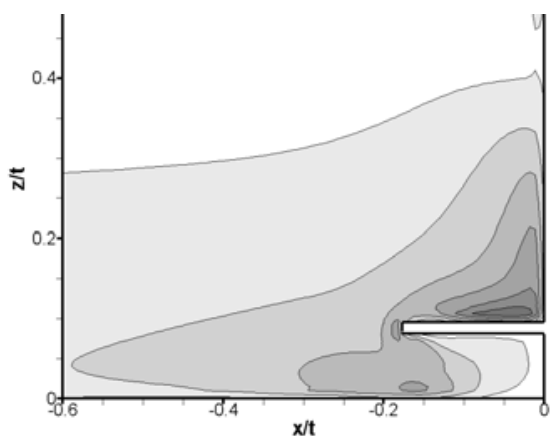

(b) Parametric Study of Cho[5]

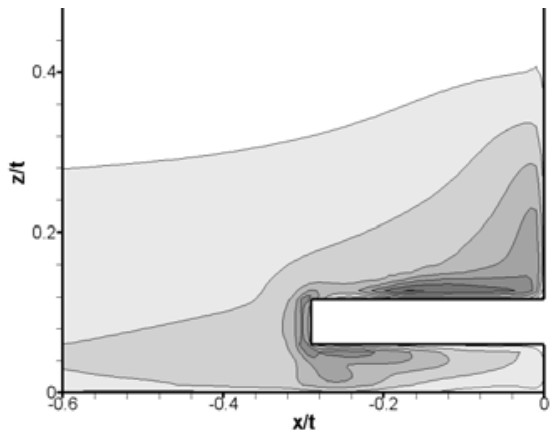

(c) Optimized Design

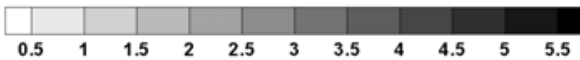

Fig. 5. Contours of Adjusted NTKE at Leading Edge Plane

Fig. 7(a) (c)는 각 형상에 대한 날개 앞전 면 에서의 수정 $\mathrm{C}_{\mathrm{Pt}}\left(\mathrm{C}_{\mathrm{Ptad}}\right)$ 값으로 $\mathrm{NTKE}_{\mathrm{ad}}$ 값과 같은 방법으로, 날개 앞전 면에서의 $\mathrm{C}_{\mathrm{Pt}}$ 값을 기준 모 델의 질량가중평균한 $\mathrm{C}_{\mathrm{Pt}}$ 값으로 나눈 것이다. Fig. 7(a)의 기준 모델에서 볼 수 있듯이, 날개 앞전 면에서 발생한 강한 말굽와류와 모서리 와 류, 날개면에서 바닥면으로 흐르는 유동 등이 바 닥면의 낮은 운동에너지를 갖는 경계층 영역을 통과하면서 발생하는 점성 저항에 의해 전압

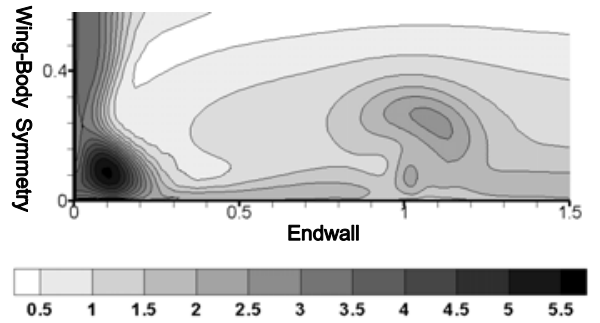

Fig. 6. Contours of Adjusted NTKE at $x / t=$ 4.46 Plane

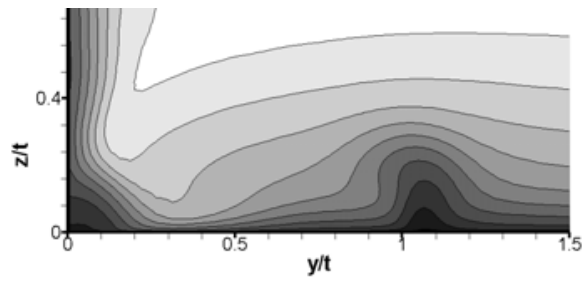

(a) Baseline, No Fence

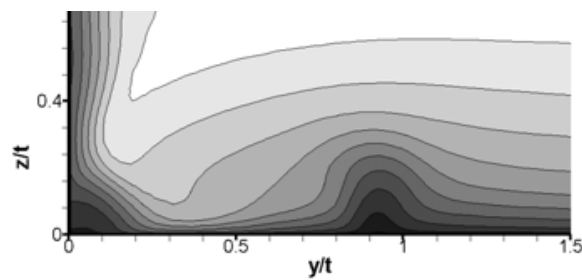

(b) Parametric Study of Cho[5]

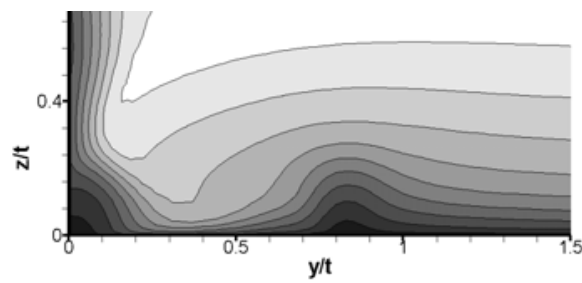

(c) Optimized Design

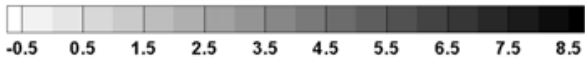

Fig. 7. Contours of Adjusted $\mathrm{C}_{\mathrm{Pt}}$ at $\mathrm{x} / \mathrm{t}=4.46$ Plane

력 손실이 발생하는 것을 볼 수 있다. 특히, $\mathrm{y} / \mathrm{t}$ 가 약 1.1 인 지점에서 높게 나타나는 것을 알 수 있다. Cho[5] 결과의 경우, 날개 앞전 판에 의해 말굽와류의 강도가 줄어듦에 따라 그 정도가 감 소한 것을 볼 수 있으며, $\mathrm{y} / \mathrm{t}$ 가 약 0.9 인 지점에 서 높게 나타나는 것을 알 수 있다. 기준 모델에 비해 전압력 손실이 높게 나타나는 지점이 날개 면 쪽에 더 근접한 것을 알 수 있다. 최적화 결 과의 경우, 반대방향으로 회전하는 말굽와류로 
Table 3. Summary of Benefit for Optimized Leading Edge Fence Shape

\begin{tabular}{c|c|c|c}
\hline Cases & $\begin{array}{c}\text { Max. NTKE } \\
\text { at Leading } \\
\text { Edge plane }\end{array}$ & $\begin{array}{c}\text { NTKE } \\
\text { at Leading } \\
\text { Edge plane }\end{array}$ & $\begin{array}{c}\mathrm{C}_{\mathrm{Pt}} \\
\text { at } \mathrm{x} / \mathrm{t}=4.46 \\
\text { plane }\end{array}$ \\
\hline \hline Baseline & 0.03195 & 0.00563 & 0.10088 \\
\hline $\begin{array}{c}\text { Parametric Study } \\
\text { of Cho[5] }\end{array}$ & $\begin{array}{c}0.02243 \\
(\mathbf{\nabla} 29.8 \%)\end{array}$ & $\begin{array}{c}0.00478 \\
(\boldsymbol{\nabla} 15.1 \%)\end{array}$ & $\begin{array}{c}0.09686 \\
(\mathbf{\nabla} 4.0 \%)\end{array}$ \\
\hline $\begin{array}{c}\text { Optimized } \\
\text { Design }\end{array}$ & $\begin{array}{c}0.02546 \\
(\mathbf{\nabla} 20.3 \%)\end{array}$ & $\begin{array}{c}0.00437 \\
(\mathbf{\nabla} 22.4 \%)\end{array}$ & $\begin{array}{c}0.09332 \\
(\mathbf{\nabla} 7.5 \%)\end{array}$ \\
\hline
\end{tabular}

인해 후류로 흐르는 와류의 강도가 상쇄 또는 약 화되어 전압력 손실이 감소되어진 것을 알 수 있 으며 전압력 손실이 높게 나타나는 지점은 $\mathrm{y} / \mathrm{t}$ 가 약 0.8 이며, $\mathrm{Cho[5]}$ 의 결과에 비해 더 날개면 쪽 에 근접한 것을 알 수 있다.

Table 3은 기준 모델에 대한 $\mathrm{Cho[5]의} \mathrm{설계와}$ 근사최적화 기법을 이용한 설계에 대한 유동특성 의 향상정도를 나타낸 표이다. 날개 앞전 면 NTKE의 최대값의 경우, $\mathrm{Cho[5]}$ 의 설계는 $29.8 \%$ 가 감소한 반면, 근사최적화을 통한 설계는 $20.3 \%$ 가 감소하였다. 이는 앞전 판의 윗면에서 발생하 는 시계반대방향으로 회전하는 말굽와류에 의한 것이다. 그리고 질량가중평균한 날개 앞전 면의 NTKE는 근사최적화를 통한 설계 결과가 Cho[5] 의 설계에 비해 감소비율이 더 증가하였다. 또한, $\mathrm{x} / \mathrm{t}$ 가 4.46 인 면에서의 기준 모델 대비 $\mathrm{C}_{\mathrm{Pt}}$ 의 감소 비율의 경우, 근사최적화를 통한 설계가 Cho[5]의 설계에 따른 감소비율 $(4.0 \%)$ 보다 $3.5 \%$ 더 감소한 $7.5 \%$ 를 나타내었다.

\section{4. 결 론}

날개 바닥면의 낮은 운동에너지를 갖는 경계 층 영역을 통과하는 와류로 인해 발생하는 점성 저항은 전압력 손실로 나타나므로, 날개 앞전의 말굽와류 발생을 제어하여 날개 후류에서의 전압 력 손실을 감소시키기 위한 여러 방법들이 예전 부터 논의 되었다.

본 논문에서는 여러 방법들 중에서 $\mathrm{Cho[5]}$ 에 의해 연구된 날개 앞전 판에 의한 말굽와류 발생 제어 방법에 대해 근사최적화 기법을 이용한 최 적화를 실시하였다.
최적화 결과를 통해, 기준 모델의 경우와 반대 방향으로 회전하는 말굽와류가 발생하였으며, 이 렇게 발생한 말굽와류로 인해 후류로 흐르는 다 른 와류와 상호작용함으로써 와류의 강도가 상쇄 또는 약화되어 전압력 손실이 감소되었으며, 기 준 모델 대비 전압력 손실계수 $\left(\mathrm{C}_{\mathrm{Pt}}\right)$ 가 $7.5 \%$ 감소 하였다.

\section{후 기}

본 연구는 한국과학재단을 통해 교육과학기술 부의 우주기초원천기술개발 사업(NSL, National Space Lab., 2008-2006289)의 지원을 받아 수행된 연구임.

\section{참고문헌}

1) Eckerle, W. A. and Langston, L. S., "Horseshoe Vortex Formation Around a Cyliner", Trans. ASME, Journal of Turbomachinery, Vol. 109, 1987, pp. 278 285.

2) Kubendran, L. R. and Harvey, W. D. Juncture Flow Control Using Leading-Edge Fillets, 1985, AIAA-85-4097.

3) Devenport, W. J., Simpson, R.L., Dewitz, M.B and Agarwal, N.K. "Effects of a Leading-Edge Fillet on the Flow Past an Appendage-Body Junction", AIAA J., Vol. 30, No. 9, 1992, pp. 2177-2183.

4) Zess, G. A. and Thole, K. A., "Computational Design and Experimental Evaluation of Using a Leading Edge Fillet on a Gas Turbine Vane", Journal of Turbomachinery, Vol. 124, 2002, pp. 167-175.

5) 조종재, 김귀순, "일반적인 날개 형상에서의 앞전 판에 의한 말굽와류 제어", 한국항공우주학 회지, Vol. 37, No. 4, 2009, pp. 336-343.

6) Olcmen, S. and Simpson, R., "An experimental study of a three-dimensional pressuredriven turbulent boundary layer", Journal of Fluid Mechanics, Vol. 290, 1995, pp. 225-262.

7) Olcmen, S. and Simpson, R., "Some features of a turbulent wing-body junction vortical flow", 35th Aerospace Sciences Meeting and Exhibit, 1997, AIAA-97-0651.

8) Jones, D. and Clarke, D., "Simulation of a Wing-Body Junction Experiment using the 
Fluent Code", Dsto-tr-1731, Defence Science and Technology Organization, Australian Government, Department of Defense, 506 Lorimer St., Fishermans Bend, Victoria 3207, Australia, 2005.

9) Yakhot, V. and Orszag, S. A., "Renormalization Group Analysis of Turbulence. 1. Basic Theory", Journal of Science Computation, Vol. 1, 1986, pp. 3-51.

10) Bates, J. S., Sienz, J. and Toropov, V. V.,
"Formulation of the Optimal Latin Hypercube Design of Experiments Using a Permutation Genetic Algorithm", AIAA / ASME / ASCE / AHS / ASC Structures, Structural Dynamics \& Materials Conference, 2004, AIAA Paper 2004-2011.

11) Myers, R. H. and Montgomery, D. C., "Response Surface Methodology - Process and Product Optimization Using Designed Experiments", John Wiley \& Sons, New York, 1995. 